\title{
Uso de vídeo com narrativa digital como proposta para instigar a motivação em cursos a distância
}

\author{
Use of video with digital storytelling as a proposal to instigate \\ motivation in distance learning courses
}

\section{Uso del video con narrativa digital como propuesta para incentivar la motivación en los cursos a distancia}

\author{
Valter Luís de Avellar \\ Universidade Católica de Pernambuco - PB - Brasil \\ ORCID: https://orcid.org/0000-0002-0806-8662 \\ Endereço Currículo Plataforma Lattes: http://lattes.cnpq.br/2453533818170693 \\ E-mail: valter.avellar@unicap.br \\ Fernanda Paiva Furtado da Silveira \\ Universidade Católica de Pernambuco - PB - Brasil \\ ORCID: https://orcid.org/0000-0001-6136-7808 \\ Endereço Currículo Plataforma Lattes: http://lattes.cnpq.br/1567062268710500 \\ E-mail: fernandasilveira.unicap@gmail.com
}

Resumo: A Educação a Distância tem como um de seus desafios manter o aluno motivado. Uma das formas de vencer esse desafio é produzir material didático de qualidade. Portanto, este artigo tem como objetivo propor a produção de vídeo com narrativa digital, como estratégia para instigar a motivação do aluno, melhorar as interações no ambiente virtual e revitalizar o material didático de uma disciplina a distância. $\mathrm{O}$ artigo foi desenvolvido a partir de uma pesquisa qualitativa de caráter exploratório e as teorias da aprendizagem multimídia (Richard Mayer), da carga cognitiva (John Sweller) e da distância transacional (Michael Moore) embasaram este estudo.

Palavras-chave: Narrativas digitais. Educação a distância. Vídeo. Material didático para EaD. Motivação.

\begin{abstract}
One of the challenges of Distance Education is to keep the student motivated. One of the ways to overcome this challenge is to produce quality teaching material. Therefore, this article aims to propose video production with digital storytelling, as a strategy to instigate student motivation, improve interactions in the virtual environment and revitalize the didactic material of a distance course. The article was developed from an exploratory qualitative research and the theories of multimedia learning (Richard Mayer), cognitive load (John Sweller) and transactional distance (Michael Moore) supported this study.
\end{abstract}




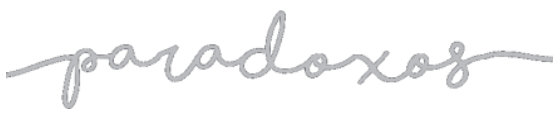

Uso de vídeo com narrativa digital

como proposta para instigar a

motivação em cursos a distância

SILVEIRA, AVELLAR, 2021

Keywords: Digital storytelling. Distance education. Video. Didactic material for distance education. Motivation.

Resumen: Uno de los retos de la Educación a Distancia es mantener motivado al alumno. Una de las formas de superar este desafío es producir material didáctico de calidad. Por tanto, este artículo tiene como objetivo proponer la producción de videos con narrativa digital, como una estrategia para instigar la motivación del alumno, mejorar las interacciones en el entorno virtual y revitalizar el material didáctico de un curso a distancia. El artículo se desarrolló a partir de una investigación cualitativa exploratoria y las teorías del aprendizaje multimedia (Richard Mayer), la carga cognitiva (John Sweller) y la distancia transaccional (Michael Moore) apoyaron este estudio.

Palabras clave: Narrativas digitales. Educación a distancia. Vídeo. Material didáctico para la educación a distancia. Motivación.

\section{Introdução}

A Associação Brasileira de Educação a Distância (ABED) em seu último censo sobre Educação a Distância (EaD) mostrou que, em 2018, os matriculados em cursos a distância passaram dos 9 milhões (ABED, 2019, p. 61), indicando o quanto essa modalidade de ensino vem sendo uma opção bastante procurada pelas pessoas que querem algum tipo de formação. Grande parte desse público é de pessoas adultas, que têm entre 26 e 40 anos, sendo que

[...] esse público já está inserido no mercado de trabalho e tem compromissos relativos à subsistência de sua família; a escolha por essa modalidade, portanto, provavelmente ocorre em virtude da flexibilidade de horário e de acesso possibilitada pela EAD. (ABED, 2019, p. 52)

Diante desse cenário, é possível perceber que, pela faixa etária indicada acima, esse público está “em fase de formação profissional ou contínua, com mais autonomia, porém com menos disponibilidade de horário e menos possibilidades de deslocamentos." (ABED, 2019, p. 52).

É preciso, então, que um curso a distância seja bem planejado, elaborado e executado para que as expectativas do seu público-alvo sejam atingidas e que o interesse desse público se mantenha durante todo o processo de ensino aprendizagem. 


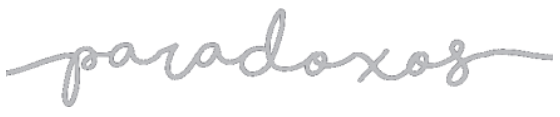

Uso de vídeo com narrativa digital como proposta para instigar a motivação em cursos a distância

SILVEIRA, AVELLAR, 2021

O sucesso de um curso a distância depende de vários fatores, sendo um dos principais a produção de material didático de qualidade (BENTO, 2015, p. 11). O material didático deve estar alinhado, entre outros quesitos, aos objetivos de aprendizagem e às características do público-alvo.

Segundo Filatro,

[...] quando pensamos em conteúdos para a educação a distância, estamos falando em recursos educacionais que são registrados em diferentes mídias (como a mídia impressa e digital, incluindo a multimídia e a hipermídia) e veiculados por diferentes tecnologias (eletrônicas, digitais, móveis). (2018, p. 42)

O material didático bem elaborado e disposto em diferentes meios facilita o aprendizado e faz com que o aluno $\mathrm{EaD}$ mantenha o interesse no curso.

No entanto, sejam quais forem as formas de apresentação do material didático, é preciso que ele seja "um canal de comunicação entre o aluno, o professor e o conteúdo, sua linguagem necessita ser direta e de fácil interpretação.” (SANTOS, 2017, p. 49).

Então, como esse canal de comunicação pode ser melhorado, a fim de manter o engajamento do aluno num curso a distância? Será que a produção de vídeos usando narrativas digitais pode ser uma boa estratégia metodológica para esse fim?

Este artigo, portanto, tem como objetivo propor a produção de vídeo com narrativa digital como estratégia para manter o enganjamento, instigar a motivação do aluno, melhorar as interações aluno-professor e aluno-conteúdo e revitalizar o material didático da disciplina Religião, Ciência e Tecnologia, que faz parte da grade curricular do curso de graduação a distância em Ciências da Religião, ofertado pela Universidade Católica de Pernambuco (UNICAP). Os objetivos específicos deste estudo são: realizar uma pesquisa bibliográfica, a fim de conhecer os principais conceitos e teorias relacionados ao tema deste artigo; entender como vídeos e narrativas digitais podem contribuir para manter o engajamento e a motivação do aluno EaD; definir critérios para a proposta de produção do vídeo com narrativa digital; elencar as etapas que deverão ser seguidas no processo de produção do vídeo; listar possíveis resultados caso a proposta venha a ser implementada na disciplina, fazer uma breve análise do estudo feito para este artigo.

DOI: http://doi.org/10.14393/par-v6n1-2021-57147 - Paradoxos, Uberlândia, v. 6, n. 1, p. 21-37, jan./jun. 2021| 23 


\section{Justificativa}

Visando a qualidade da $\mathrm{EaD}, 46,67 \%$ das instituições de ensino, com cursos regulamentados totalmente a distância em 2018 no Brasil, se preocupam em revisar anualmente o conteúdo dos seus cursos e $66,67 \%$ dessas instituições produzem os conteúdos com mão de obra interna (ABED, 2019, p. 166-167).

A Universidade Católica de Pernambuco (UNICAP) também preocupa-se em manter a qualidade de seus cursos, inclusive os oferecidos na modalidade EaD:

Os cursos de graduação a serem ministrados na modalidade $\mathrm{EaD}$, [...], devem preservar o padrão de qualidade exigido pela UNICAP para os cursos presenciais e obedecer às Diretrizes Curriculares e Nacionais e demais legislações vigentes para essa modalidade de ensino. (UNICAP, 2017, p. 47-48)

Por isso, de acordo com o Plano de Gestão da EaD UNICAP vigente, o material didático dos cursos a distância, disponibilizados no ambiente virtual de aprendizagem, deve ser revisado semestralmente (UNICAP, 2018, p. 35-36).

Pensando não só na qualidade do material didático dos cursos a distância da UNICAP, mas, também, em como esse material pode ser apresentado em outros formatos, este artigo vem propor a produção de vídeo com narrativa digital para uma disciplina da graduação a distância em Ciências da Religião, como forma de revitalizar o material didático, a fim de motivar e engajar cada vez mais o aluno EaD dessa instituição de ensino.

Sabe-se que quase $78 \%$ das instituições de ensino, com cursos totalmente a distância regulamentados em 2018, fazem uso de vídeos de diferentes gêneros que não sejam teleaulas (ABED, 2019, p. 183). O vídeo, segundo Moore e Kearsley (2008, p. 82), “é uma mídia poderosa para atrair e manter a atenção e para transmitir impressões." Por esse motivo, o vídeo foi o formato de apresentação do conteúdo escolhido para essa proposta de revitalização do material didático da disciplina Religião, Ciência e Tecnologia.

No entanto, elaborar um vídeo "exige criatividade e conhecimento profissional especializado para a produção de material de qualidade, que promova interação e que seja atrativo para o aluno." (SOUZA, 2016, p. 35). Diante disso, pensou-se como o conteúdo poderia ser trabalhado no vídeo, a fim de ser atraente 


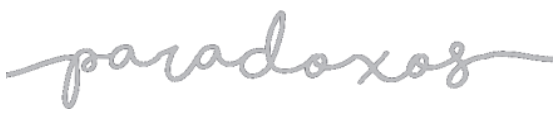

Uso de vídeo com narrativa digital como proposta para instigar a motivação em cursos a distância

SILVEIRA, AVELLAR, 2021

e, ao mesmo tempo, criativo. Aí, então, surge a ideia de usar narrativas para desempenhar essas funções. Como se sabe, uma história bem contada sempre atrai a atenção e fica na lembrança de quem a ouviu. Filatro e Cairo dizem que "Desde sempre, o ato de narrar e ouvir narrativas fascina a humanidade. A narrativa é uma das primeiras formas - e talvez a mais natural - utilizada pelos seres humanos para organizar sua experiência e seu conhecimento.” (2015, p. 270)

Por essa razão, pensou-se em criar vídeo com narrativa digital, uma vez que esta pode integrar imagens, sons, animações e, até, quizzes interativos, que poderão surgir no decorrer da história. A intenção é que o aluno se sinta envolvido com o conteúdo e se interesse cada vez mais pelo tema e, consequentemente, pela disciplina.

Religião, Ciência e Tecnologia foi a disciplina escolhida para implementar essa proposta. Ela tem como objetivo investigar e discutir relações e interações históricoculturais e político-sociais entre ciência, tecnologia e religião, buscando identificar referenciais na perspectiva da fraternidade e do bem viver.

Como já informado, a disciplina é parte integrante da grade curricular do curso a distância em Ciências da Religião. Esse curso foi o primeiro a ser ofertado na modalidade EaD pela UNICAP e já foram ministradas duas turmas, iniciadas nos semestres 2019.1 e 2019.2, no formato de segunda licenciatura, com duração de um ano. A partir do segundo semestre de 2020, será ofertada a primeira turma de Ciências da Religião em formato de licenciatura plena, com duração de quatro anos, também na modalidade a distância.

Os motivos da escolha da disciplina Religião, Ciência e Tecnologia foram: (1) o tema da disciplina, por se tratar do uso da tecnologia midiática e da internet pelas religiões e movimentos religiosos; (2) conter conteúdos do material didático que podem ser trabalhados por meio do gênero narrativo; (3) o professor da disciplina já faz uso de outras estratégias para motivar e incentivar os alunos, como a gamificação e dinâmicas em grupos; (4) com as estratégias já utilizadas, percebeu-se uma significativa participação e bom aproveitamento dos alunos nas duas turmas já oferecidas; (5) o professor é muito atuante na mediação dos alunos durante o processo ensino aprendizagem e tem interesse em conhecer e implementar novos métodos que proporcionem o engajamento dos alunos; (6) a avaliação da disciplina, respondida pelos alunos das turmas concluintes, teve resultado muito positivo, com bastante elogios sobre a metodologia adotada durante as aulas e sobre a conduta mediadora do professor. 


\section{Aspectos Teóricos e Metodológicos}

Este artigo foi desenvolvido a partir de uma pesquisa qualitativa de caráter exploratório. As teorias que embasaram este estudo foram: a teoria da aprendizagem multimídia, de Richard Mayer, a teoria da carga cognitiva, elaborada por John Sweller, e a teoria da distância transacional, criada por Michael G. Moore. Também foram pesquisados métodos para a elaboração de conteúdos para $\mathrm{EaD}$, em especial, produção de vídeos, baseados na bibliografia de Andrea Filatro e outros autores que escrevem sobre esse tema.

Além disso, foram feitas consultas a e-books disponíveis na biblioteca digital da UNICAP e pesquisas na página Periódicos Capes para buscar artigos relacionados à ideia central deste estudo.

\subsection{Teoria da Aprendizagem Multimídia}

A teoria da aprendizagem multimídia foi desenvolvida pelo professor de psicologia norte americano Richard Mayer e, resumidamente, ela diz que "as pessoas aprendem melhor a partir de palavras e imagens do que somente com palavras". (MAYER, 2009, p. 1). “A teoria se aplica ao uso associado de palavras e imagens em recursos de ensino e aprendizagem, tais como livros, animações, vídeos, jogos e outras produções." (SILVA; MONTANÉ, 2017, p. 2)

A ideia é que, quando dois ou mais canais de processamento são usados adequadamente, eles contribuem mais para o processamento e a retenção da informação do que um único canal. Isto é, os benefícios de usar diferentes linguagens e mídias são aditivos, somam-se. (FILATRO, 2018, p. 49)

A teoria de Mayer possui vários princípios e alguns deles servirão de base para a proposta de produção do vídeo com narrativa digital para a disciplina Religião, Ciência e Tecnologia: 
Quadro 1: Princípios da teoria da aprendizagem multimídia para produção de vídeo com narrativa digital para disciplina $\mathrm{EaD}$

\begin{tabular}{|l|l|}
\hline Princípio da coerência & materiais sem relevância não serão utilizados. \\
\hline Princípio da segmentação & $\begin{array}{l}\text { sempre que necessário, as informações serão divididas } \\
\text { em partes menores para se adquarem ao ritmo de } \\
\text { aprendizagem do aluno. }\end{array}$ \\
\hline Princípio da personalização & $\begin{array}{l}\text { as falas e textos do vídeo deverão ser em linguagem } \\
\text { dialógica. }\end{array}$ \\
\hline Princípio da sinalização & materiais com relevância serão destacados. \\
\hline Princípio do pré-treinamento & $\begin{array}{l}\text { nomes e características dos conceitos do conteúdo abordado } \\
\text { serão previamente apresentados. }\end{array}$ \\
\hline Princípio da voz & a narração deverá ser feita por uma voz humana. \\
\hline Princípio da redundância & $\begin{array}{l}\text { textos que aparecerão escritos no vídeo não deverão ser lidos } \\
\text { exatamente como estão transcritos. }\end{array}$ \\
\hline Princípio de multimídia & $\begin{array}{l}\text { Ouzer usos de textos e imagens em vez de somente textos. } \\
\text { áudios e testes rápidos, do tipo quizz, durante a execução do } \\
\text { vídeo, para que o aluno interaja com o conteúdo. }\end{array}$ \\
\hline Princípio da proximidade & $\begin{array}{l}\text { textos devem estar próximos às imagens e se houver } \\
\text { apresentação de gráficos, a locução deve ser simultânea a eles. }\end{array}$ \\
\hline Princípio da modalidade & $\begin{array}{l}\text { as imagens devem ser complementadas, preferencialmente, } \\
\text { com texto narrado. }\end{array}$
\end{tabular}

Fonte: adaptado de Filatro (2018, p. 49)

Os princípios acima estão relacionados à teoria da carga cognitiva, elaborada por John Sweller (FILATRO, 2018, p. 49). Essa teoria diz respeito ao modo como os indivíduos processam as informações, sendo que a aprendizagem será mais efetiva se o volume de informações apresentadas ao indivíduo for compatível com a sua capacidade de processamento (FILATRO, 2018, p. 49-50).

Portanto, para a elaboração do vídeo com narrativa digital da disciplina Religião, Ciência e Tecnologia os conhecimentos dessas duas teorias serão fundamentais para que o produto final esteja com a medida certa de informação para não haver uma sobrecarga cognitiva.

\subsection{Teoria da Distância Transacional}

A teoria da distância transacional, criada por Michael G. Moore, pode ser explicada da seguinte maneira: 


\begin{abstract}
A transação a que denominamos Educação a Distância ocorre entre professores e alunos num ambiente que possui como característica especial a separação entre alunos e professores. Esta separação conduz a padrões especiais de comportamento de alunos e professores. A separação entre alunos e professores afeta profundamente tanto o ensino quanto a aprendizagem. Com a separação surge um espaço psicológico e comunicacional a ser transposto, um espaço de potenciais mal-entendidos entre as intervenções do instrutor e as do aluno. Este espaço psicológico e comunicacional é a distância transacional. (MOORE, 2002, p. 2)
\end{abstract}

Essa teoria, em resumo, estuda os fatores que influenciam na percepção de proximidade psicológica e comunicacional nas relações aluno-professor, alunoaluno e aluno-conteúdo, especialmente, na Educação a Distância. Esses fatores estão relacionados a três grupos de variáveis: diálogo, estrutura e autonomia do Aluno (MOORE, 2002, p. 3).

O diálogo refere-se às interações entre os agentes (professor, aluno e conteúdo) de um curso. Essas interações podem ser negativas, neutras ou positivas, porém, nessa teoria, são tratadas apenas as formas de diálogo que possuem qualidades positivas entre os agentes nas interações, sendo, estes, ativos e que colaboram uns com os outros (MOORE, 2002, p. 3). Os meios de comunicação, por sua natureza interativa, têm um forte impacto no que diz respeito ao diálogo e podendo ser manipulados é possível aumentar o diálogo nas interações, diminuindo, assim, a distância transacional (MOORE, 2002, p. 3-4).

Porém, Moore ressalta que

[...] uma forma de diálogo entre professor e aluno acontece mesmo em programas que não possuem qualquer interação, tal como quando o aluno estuda através de materiais impressos autoinstrucionais, ou por meio de fitas de áudio ou de vídeo. Mesmo nestes meios há alguma forma de diálogo aluno-instrutor, pois o aluno desenvolve uma interação silenciosa e interior com a pessoa que, distante no tempo e no espaço, organizou um conjunto de idéias ou informações para transmissão, dentro daquilo que poderia ser considerado como um "diálogo virtual" com um leitor, espectador ou ouvinte distante e desconhecido. (2002, p. 4)

Sendo assim, podemos concluir que quanto mais dialógico for o material didático produzido para $\mathrm{EaD}$, menor será a distância transacional sentida pelo aluno. 


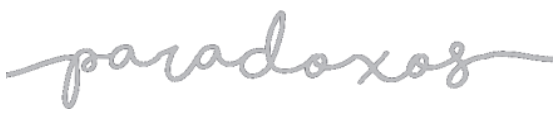

Uso de vídeo com narrativa digital como proposta para instigar a motivação em cursos a distância

SILVEIRA, AVELLAR, 2021

A estrutura do programa é o segundo fator e refere-se às formas como um programa de ensino é estruturado para ser transmitido pelos diferentes meios de comunicação e, portanto, também influenciam na distância transacional (MOORE, 2002, p. 5).

Se um curso tiver design aberto, no qual a possibilidade de diálogos entre professores e alunos é mais frequente, a estrutura não precisa ser altamente elaborada, uma vez que informações e orientações complementares podem ser conseguidas por meio dos diálogos diretos com os professores (MOORE, 2002, p. 5). No entanto, é preciso que professores e alunos sejam atuantes no processo ensino-aprendizagem, pois, do contrário, a distância transacional será bastante percebida por eles.

Em cursos com a estrutura fechada, como é o caso dos cursos autoinstrucionais, é preciso que todo o material seja elaborado de modo que o aluno tenha o máximo de informações possíveis sobre o conteúdo para conseguir prosseguir sozinho e, então, neste caso, o material e os meios de comunicação escolhidos devem manter um nível de diálogo alto para que a distância transacional seja a menor possível (MOORE, 2002, p. 5).

O terceiro e o último fator é a autonomia do aluno. Durante os estudos da teoria da distância transacional, que geraram os conceitos de distância, diálogo e autonomia, alguns dados sugeriram padrões de personalidade (MOORE, 2002, p. 8):

[...] alunos que preferiam ou que se saíam bem em programas de ensino que eram mais acentuadamente dialógicos e menos estruturados, ao lado daqueles que preferiam ou que se saíam bem em programas menos dialógicos e mais estruturados. Também ficou evidente que diversos alunos usavam materiais didáticos e programas de ensino para atingir seus próprios objetivos, à sua maneira e sob seu próprio controle. (MOORE, 2002, p. 9).

E para explicar esse processo, surgiu, então, o conceito de autonomia do aluno “[...] é a medida pela qual, na relação ensino/aprendizagem, é o aluno e não o professor quem determina os objetivos, as experiências de aprendizagem e as decisões de avaliação do programa de aprendizagem." (MOORE, 2002, p. 9).

Pode-se concluir, portanto, que quanto mais o aluno estiver seguro e envolvido no seu processo de aprendizagem, menor será a percepção da distância transacional sentida por ele num curso. 


\subsection{Vídeos e Narrativas Digitais na EaD}

Como já mencionado, o material didático de um curso EaD virtual pode ser apresentado ao aluno em diversos formatos. Um desses formatos é o vídeo.

De acordo com Moran,

O vídeo explora [...], basicamente, o ver, o visualizar, o ter diante de nós as situações, as pessoas, os cenários, as cores, as relações espaciais [...]. Desenvolve um ver entrecortado, com múltiplos recortes da realidade, através dos planos e muitos ritmos visuais: imagens estáticas e dinâmicas, câmera fixa ou em movimento, uma ou várias câmeras, personagens quietos ou movendo-se, imagens ao vivo, gravadas ou criadas no computador. Um ver que está situado no presente, mas que o interliga não-linearmente com o passado e com o futuro. (1995, p. 28, grifo do autor)

Graças às tecnologias de informação e comunicação (TIC), o vídeo é um recurso pedagógico bastante utilizado na $\mathrm{EaD}$ e, dentre outros, ele favorece o processo de ensino aprendizagem (ROOVER et al., 2006, p. 136), uma vez que "é capaz de [...] motivar e prender a atenção, pois provoca todos os sentidos; é um recurso audiovisual que, quando usado de forma coerente, tem grande potencial educativo." (ROOVER et al., 2006, p. 136).

Segundo Filatro e Cairo, na EaD, os conteúdos são o ponto de partida da interação do aluno com o ambiente educacional no qual ele está inserido (2015, p. 3). Portanto, o vídeo "como conteúdo de ensino, ou a videoaula, é mais uma forma de interatividade entre professor e aluno [...]" (ROOVER et al., 2006, p. 136) e, também, entre aluno e conteúdo.

A partir dessas considerações sobre vídeo, chegou-se à ideia de que esse recurso educacional poderá ser uma forma de incrementar o material didático da disciplina EaD Religião, Ciência e Tecnologia. Porém, ainda era preciso identificar que tipo de vídeo poderia servir para motivar e engajar o aluno, a fim de tornar seu aprendizado mais prazeroso e, ao mesmo tempo, significativo. O tipo de vídeo escolhido tem como base os estudos das teorias já descritas neste artigo e, também, com o que José Morán menciona a seguir:

O ver está, na maior parte das vezes, apoiando o falar, o narrar, o contar histórias. A fala aproxima o vídeo do cotidiano, de como as pessoas se comunicam habitualmente. Os diálogos, em geral, expressam a fala coloquial, enquanto o narrador (normalmente em off) "costura" as cenas, as outras falas, dentro da norma culta, orientando a 
significação do conjunto. A narração falada ancora todo o processo de significação. (1995, p. 28, grifo do autor)

A partir disso, o tipo de vídeo que será proposto para a revitalização do material didático da disciplina EaD Religião, Ciência e Tecnologia é o que utiliza narrativa.

Segundo Almeida e Valente,

a narrativa pode ser vista como uma "janela" na mente do aprendiz, permitindo entender o nível de conhecimento, do qual ele dispõe sobre os conteúdos e temas trabalhados. A explicitação deste conhecimento permite que o educador possa conhecer o nível de conhecimento do aprendiz e, assim, intervir e auxiliá-lo na depuração desses conceitos, de modo que conhecimentos mais sofisticados possam ser construídos. (2012, p. 64)

Para trabalhar as narrativas na $\mathrm{EaD}$ de forma que as tornem mais dinâmicas e que sejam atraentes para o aluno, as TIC são fundamentais, pois "recursos digitais [...] podem ser utilizados para animar as histórias, torná-las mais imagéticas, sonoras e dinâmicas." (ALMEIDA; VALENTE, 2012, p. 65) Com a ajuda das TIC a arte de contar histórias transforma-se em narrativas digitais.

As narrativas digitais podem contar uma boa história unindo, num só produto, imagens, sons, textos falados e escritos, animações, efeitos visuais e, ainda, elementos interativos, como quizzes.

É por essas características que produzir vídeos educacionais com o uso de narrativas digitais para $\mathrm{EaD}$ é uma estratégia muito bem-vinda sempre que a intenção for manter a atenção e o envolvimento do aluno e deixá-lo motivado ao longo do seu trajeto num curso a distância.

\subsection{Critérios e Etapas da Produção do Vídeo com Narrativa Digital para Disciplina EaD}

Para a produção do vídeo com narrativa digital para a disciplina EaD Religião, Ciência e Tecnologia, deverão ser levados em consideração os seguintes critérios:

a. será produzido, inicialmente, apenas um vídeo com narrativa digital;

b. o vídeo deverá ser um material complementar de uma das unidades escolhidas no material didático já existente da disciplina;

c. o tempo de duração do vídeo deverá ser, máximo, de oito minutos, já contando com vinhetas e créditos finais; 


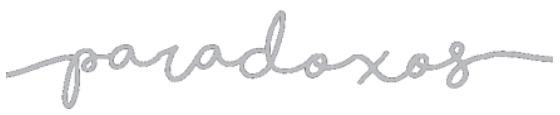

Uso de vídeo com narrativa digital como proposta para instigar a motivação em cursos a distância

SILVEIRA, AVELLAR, 2021

d. a narrativa digital deverá conter os elementos que compõem uma narrativa: “personagens, ações, tempo, espaço e narrador" (FILATRO; CAIRO, 2015, p. 272) e deverá ser contada de forma criativa, contendo, no mínimo, três tipos de mídia, que podem ser imagens, sons, textos (falados ou escritos), animações, efeitos visuais ou outros, para que a história seja envolvente e conquiste a atenção do aluno para o conteúdo abordado;

e. para o planejamento e a produção/edição do vídeo, deverão ser usados os recursos (mão de obra, estrutura, equipamentos e softwares) que a UNICAP já possui;

f. no caso dos softwares para produção/edição do vídeo, a equipe deverá usar os que a instituição já tem licença ou a fazer uso de softwares livres.

g. nas etapas da produção do vídeo, apresentadas a seguir, será imprescindível a participação de diversos profissionais, como designer instrucional, profissionais especialistas em produção/edição de vídeo, consultor pedagógico, professor executor da disciplina Religião, Ciência e Tecnologia e outros que, por ventura, precisarem participar de algumas das etapas de produção. Todos deverão ser funcionários da UNICAP.

Isto posto, a produção do vídeo com narrativa digital seguirá as seguintes etapas:

Levantamento de dados: nessa primeira etapa, será feito um levantamento para conhecer o perfil do aluno; conhecer os objetivos da disciplina; saber como é a dinâmica das aulas e atividades; definir qual conteúdo/tópico, do material didático da disciplina, tem potencial para ser apresentado como um vídeo com narrativa digital; identificar, no conteúdo selecionado, quais informações, conceitos e definições são relevantes e as que merecem destaque; listar as ideias e sugestões de como o vídeo possa ser (personagens, animações, local, tempo, narração etc.).

Mapa mental: num segundo momento, os dados obtidos no levantamento servirão de base para a elaboração de um mapa mental sobre o conteúdo escolhido para o vídeo. Esse mapa vai "representar graficamente as relações entre um conjunto de tópicoschave [...]. O resultado mostra desde os conceitos mais abrangentes até os mais específicos, auxiliando a ordenação e a sequenciação hierarquizada dos conteúdos." (FILATRO, 2018, p. 60) A partir do mapa mental, serão apresentados caminhos a serem 


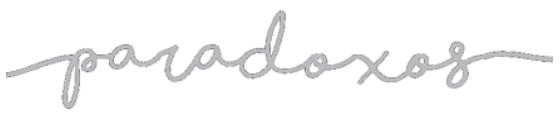

Uso de vídeo com narrativa digital como proposta para instigar a motivação em cursos a distância

SILVEIRA, AVELLAR, 2021

seguidos para a construção do vídeo, definindo os elementos da narrativa digital e, então, ser determinada uma solução final para a proposta.

Roteirização: com a ideia já formada sobre como a narrativa digital deverá ser produzida, inicia-se, então, a etapa mais importante da produção do vídeo: a roteirização. Nessa fase, será elaborado um roteiro detalhado de tudo o que será feito e falado nas cenas, incluindo, as movimentações de câmera e a sequência da apresentação das imagens e outros elementos da narrativa (FILATRO, 2018, p. 112). O roteiro serve como um guia para o restante do processo de produção.

Pré-produção: com o roteiro todo definido, será feito o levantamento de tudo que será preciso para a gravação do vídeo, como cronograma de gravações, tipos de animações e efeitos visuais, personagens e cenários a serem criados/escolhidos, definição da equipe de produção e dos equipamentos, entre outras necessidades.

Produção: esta é a fase em que o projeto sairá do papel para criar "vida". É nessa etapa que as imagens serão captadas e todas as cenas descritas no roteiro serão gravadas. No entanto, o vídeo não estará na sua versão final, pois ainda passará pela última etapa do processo, descrita a seguir.

Pós-produção: no final do processo de produção, o vídeo passará pela etapa de edição e montagem, para que as imagens, animações, efeitos e outros elementos sejam devidamente tratados. Logo após, o vídeo finalizado seguirá para validação e, sendo aprovado, poderá ser divulgado na disciplina $\mathrm{EaD}$.

Os critérios e etapas acima descritos têm a intenção de garantir que o vídeo a ser produzido tenha um padrão de qualidade satisfatório e que atenda aos objetivos da proposta sugerida neste artigo.

\section{Expectativas a serem Alcançadas}

Primeiramente, é esperado que a proposta da produção do vídeo com narrativa digital seja executada e implementada na disciplina EaD Religião, Ciência e Tecnologia. 
A partir de então, alguns bons resultados e novas propostas poderão surgir e eles serão listados a seguir, a partir da perspectiva dos três agentes que fazem parte da disciplina.

\section{Aluno:}

Aumento da produtividade dos alunos, por estarem mais motivados e interessados pelos conteúdos.

Maior engajamento dos alunos em atividades individuais e colaborativas.

Resultados ainda melhores na avaliação da disciplina, feita pelos alunos ao final do processo ensino aprendizagem.

Alunos mais autônomos e incentivados a pesquisarem outras referências, além curso, sobre os conteúdos estudados.

Melhoria no diálogo entre aluno-professor, aluno-aluno e aluno-conteúdo.

Que os alunos, futuros docentes de Ciências da Religião, consigam percerber a importância que estratégias de ensino inovadoras têm para a educação, seja ela presencial ou a distância, e que eles se tornem professores empenhados a buscarem metodologias motivadoras para aplicarem em suas trajetórias na docência.

\section{Professor:}

Satisfação do professor pela nova estratégia implementada na disciplina.

Motivação para busca de novas estratégias e metodologias que sejam criativas e que inovem o processo de ensino na EaD.

Melhoria no diálogo entre professor-aluno.

\section{Conteúdo:}

Que vídeos com narrativas digitais possam ser produzidos também pelos alunos da disciplina EaD Religião, Ciência e Tecnologia, como forma de conclusão de trabalho das dinâmicas em grupos já realizadas pelo professor durante as aulas.

Que a proposta da utilização de vídeos com narrativas digitais seja bem aceita como opção para revitalizar a forma de apresentação do material didático de outras disciplinas/cursos a distância.

Que a proposta do vídeo seja replicada em outas disciplinas EaD de outros cursos da universidade. 
Assim como os resultados positivos, também é preciso levar em consideração que resultados negativos possam acontecer. Neste caso, dependendo dos resultados negativos que surgirem, deve-se identificar se há (1) falhas de estudo, refazendo, assim, a pesquisa bibliográfica, a fim de encontrar novas teorias que possam ajudar na complementação do estudo, ou se há (2) falhas de execução durante as etapas de produção do vídeo, procurando identificar qual(is) etapa(s) precisa(m) ser melhor(es) trabalhada(s) ou se é preciso a inclusão de novas etapas ao longo do processo de produção.

\section{Considerações Finais}

A partir dos estudos feitos para este artigo, pode-se considerar que as produções que utilizam as narrativas digitais, mais especificamente os vídeos, ao integrarem elementos midiáticos, facilitam o aprendizado, comprovando, assim, que esse tipo de recurso educacional está fundamentado pela teoria da aprendizagem multimídia.

Outro fator que a proposta da produção do vídeo com narrativa digital levou em conta foi que, esse recurso, deverá ser um complemento de uma das aulas da disciplina EaD Religião, Ciência e Tecnologia e, portanto, apenas elementos essenciais do conteúdo serão abordados no vídeo. Neste caso, a teoria da carga cognitiva foi aplicada para garantir que a aprendizagem do aluno não seja prejudicada pelo excesso de informações, o que poderia causar uma sobrecarga cognitiva.

Por fim, mas não menos importante, a teoria da distância transacional teve seus conceitos sempre lembrados na proposta, pois, além de poder facilitar o processo ensino aprendizagem, o vídeo com narrativa digital também precisa proporcionar um alto grau de diálogo nas interações aluno-professor e alunoconteúdo para que o espaço emocional e comunicacional entre esses agentes seja o menor possível durante a disciplina.

Além disso, a proposta elencou critérios e caracterizou etapas imprescindíveis para a produção do vídeo com narrativa digital. Acredita-se que, com esses itens sendo seguidos, possa-se ter um produto final de qualidade e que atenda aos objetivos definidos para este estudo. 


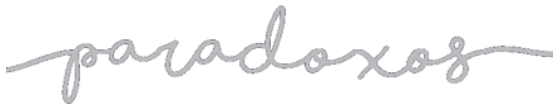

Uso de vídeo com narrativa digital como proposta para instigar a motivação em cursos a distância

Sendo assim, pode-se dizer que vídeos com narrativas digitais podem ser uma uma boa estratégia para manter o engajamento e a motivação do aluno EaD e, ao mesmo tempo, ser uma forma de revitalizar o material didático existente em um curso a distância, desde que sejam embasados nas teorias relacionadas neste artigo e que sigam, fielmente, os critérios e as etapas de produção elencados anteriormente.

Com este estudo poderão ser iniciadas novas pesquisas para levantamento de dados e averiguação de resultados obtidos a partir da implementação, em cursos/disciplinas a distância, do tipo de vídeo educacional proposto neste artigo.

\section{Referências Bibliográficas}

ABED. Censo EAD.BR: relatório analítico da aprendizagem a distância no Brasil 2018. $1^{a}$ ed. Curitiba: InterSaberes, 2019. Disponível em: http://abed.org.br/arquivos/CENSO_DIGITAL_EAD_2018_PORTUGUES.pdf. Acesso em: 16 ago. 2020.

ALMEIDA, Maria Elizabeth Bianconcini de; VALENTE, José Armando. Integração currículo e tecnologias e a produção de narrativas digitais. Revista Currículo sem Fronteiras, v.12, n.3, p.57-82, Set./Dez. 2012. Disponível em: http://www.curriculosemfronteiras.org/vol12iss3articles/almeidavalente.pdf. Acesso em 27 ago. 2020.

BENTO, Dalvaci. A produção do material didático para EaD. São Paulo: Cengage Learning, 2015. ISBN 9788522123810. Disponível em: https://integrada.minhabiblioteca.com.br/\#/books/9788522123810/. Acesso em: 19 ago. 2020.

FILATRO, Andrea; CAIRO, Sabrina. Produção de conteúdos educacionais. 1. ed. São Paulo: Editora Saraiva, 2015. ISBN 9788502635906. Disponível em: https://integrada.minhabiblioteca.com.br/\#/books/9788502635906/. Acesso em: 23 ago. 2020.

FILATRO, Andrea. Como preparar conteúdos para EAD. São Paulo: Editora Saraiva, 2018. ISBN 9788553131419. Disponível em: https://integrada.minhabiblioteca.com.br/\#/books/9788553131419/. Acesso em: 23 ago. 2020.

MAYER, Richard E. Multimedia learning. Cambridge: CUP, 2009.

MOORE, Michael. G. Teoria da distância transacional. In: KEEGAN, D. Theoretical principles of distance education. London: Routledge, 1993. p. 22-38. Tradução de: Wilson de Azevedo. Revisão de tradução de: José Manuel da Silva. Revista Brasileira de Aprendizagem Aberta e a Distância, São Paulo, v. 1, ago. 2002. DOI: https://doi.org/10.17143/rbaad.v1i0.111. 


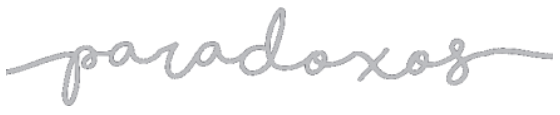

Uso de vídeo com narrativa digital
como proposta para instigar a
motivação em cursos a distância

SILVEIRA, AVELLAR, 2021

MOORE, Michael G.; KEARSLEY, Greg. Educação a distância: uma visão integrada. São Paulo: Cengage Learning, 2008. Tradução de: Roberto Galman.

MORÁN, José Manuel. O vídeo na sala de aula. Revista Comunicação e Educação, n. 2, p. 27-35, abr. 1995.

ROVER, A.; FERREIRA, A. T.; LÜCKMANN, L. C.; MOTERLE, R. R. O vídeo no processo de mediação didático-pedagógica na educação a distância. Revista Roteiro, Joaçaba, v. 31, p. 135-158, jan/dez 2006. Anual. n. 1-2. Disponível em: https://portalperiodicos.unoesc.edu.br/roteiro/article/view/8841/4873. Acesso em: 26 ago. 2020.

SANTOS, Júlio César de Carvalho. O impacto do material didático impresso nos processos de retenção ou evasão do aluno na modalidade a distância. Revista Multitexto, [S.1.], v. 5, n. 1, p. 45-56, ago. 2017. ISSN 2316-4484. Disponível em: http://www.ead.unimontes.br/multitexto/index.php/rmcead/article/view/211. Acesso em: 18 ago. 2020.

SILVA, Aline Marcelino dos Santos; MONTANÉ, Fermín Alfredo Tang. Objetos de aprendizagem baseados na teoria da aprendizagem multimídia. Revista Educacional Interdisciplinar. v. 6, n. 1, out. 2017. Disponível em:

https://seer.faccat.br/index.php/redin/article/view/616. Acesso em: 23 ago. 2020.

SOUZA, Renato Antonio de. Multimídia em educação a distância. São Paulo: Cengage Learning, 2016. ISBN 9788522123841. Disponível em:

https://integrada.minhabiblioteca.com.br/\#/books/9788522123841/. Acesso em: 23 ago. 2020.

UNICAP. Plano de desenvolvimento institucional: 2017-2022. Recife: FASA, 2017. 224 p. Disponível em: https://www1.unicap.br/wp-content/uploads/2018/09/PDI-20172022-Versa\%CC\%83o-e-MEC-06.09.2018.pdf. Acesso em: 22 ago. 2020. 